The Foundations of Newtonian Scholarship 


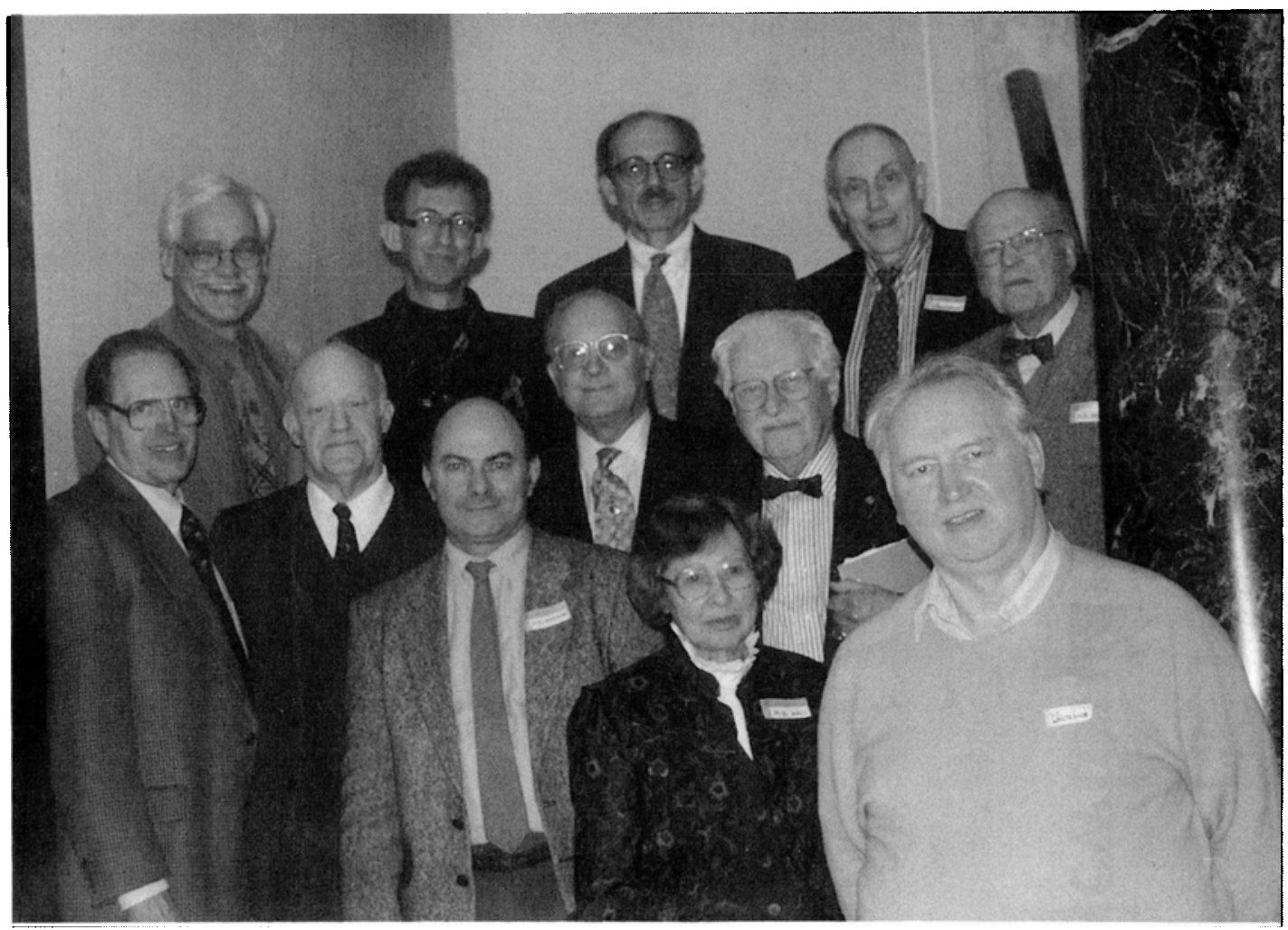

Back row (right to left): A.R. Hall, J.B. Brackenridge, A.E. Shapiro, J.G. Fauvel and M. Nauenberg.

Front row (right to left): D.T. Whiteside, I.B. Cohen, M. Boas Hall, A.H. Cook, P. Harman, R.H. Dalitz and G.E. Smith. (Photo by David Fowler). 


\title{
The Foundations of
}

Newtonian Scholarship

\author{
Editors \\ Richard H. Dalitz \\ University of Oxford, UK \\ Michael Nauenberg \\ University of California, Santa Cruz
}




\title{
Published by
}

World Scientific Publishing Co. Pte. Ltd.

P O Box 128, Farrer Road, Singapore 912805

USA office: Suite 1B, 1060 Main Street, River Edge, NJ 07661

UK office: 57 Shelton Street, Covent Garden, London WC2H 9HE

\author{
Library of Congress Cataloging-in-Publication Data \\ The foundations of Newtonian scholarship / editors, Richard H. Dalitz, Michael Nauenberg. \\ p. $\mathrm{cm}$. \\ Includes bibliographical references. \\ ISBN 9810239203 (alk. paper) \\ 1. Newton, Isaac, Sir, 1642-1727--Congresses. 2. Physics--History--Congresses. I. \\ Dalitz, R. H. (Richard Henry), 1925- II. Nauenberg, Michael.
}

Q16.N55 F68 2000

530 '.092--dc21

$99-088303$

\section{British Library Cataloguing-in-Publication Data}

A catalogue record for this book is available from the British Library.

Copyright $(\subset) 2000$ by World Scientific Publishing Co. Pte. Ltd.

All rights reserved. This book, or parts thereof, may not be reproduced in any form or by any means, electronic or mechanical, including photocopying, recording or any information storage and retrieval system now known or to be invented, without written permission from the Publisher.

For photocopying of material in this volume, please pay a copying fee through the Copyright Clearance Center, Inc., 222 Rosewood Drive, Danvers, MA 01923, USA. In this case permission to photocopy is not required from the publisher.

Printed in Singapore by Uto-Print 


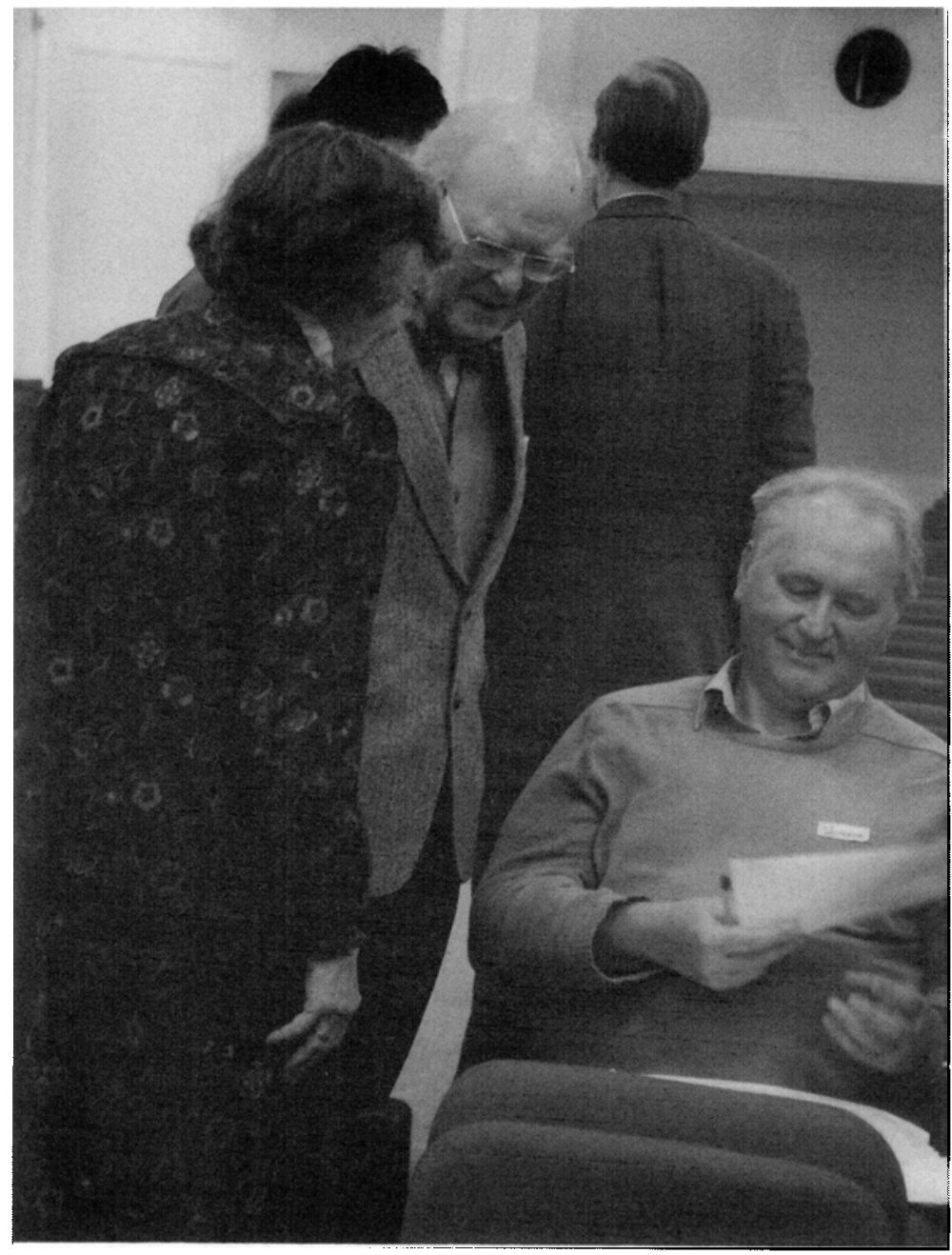

Mary and Rupert Hall talking with Tom Whiteside (seated) during a break in the morning talks. 


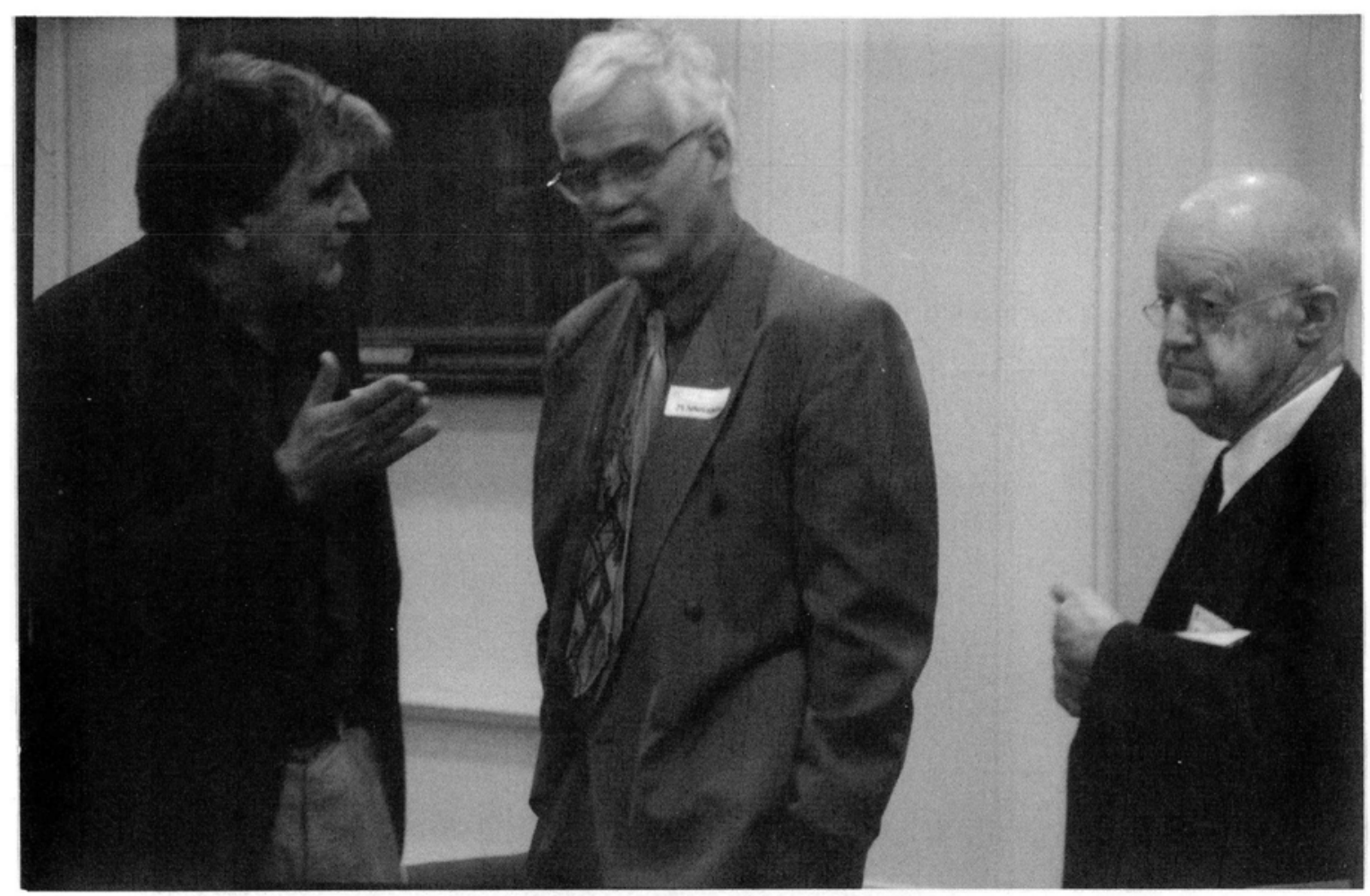

Professor D. Fowler (left) with the editors M. Nauenberg and R: Dalitz (right). 


\section{Contributors' Biographies}

J. Bruce Brackenridge is the Alice G. Chapman professor emeritus of history and physics at Lawrence University. His book The Key to Newton's Dynamics: The Kepler Problem and the Principia was published in 1995.

I. Bernard Cohen is the Victor S. Thomas professor (emeritus) of the history of science, Harvard University. Among his most recent publications are Science and the Founding Fathers: Science in the Political Thought of Franklin, Jefferson, Adams, and Madison, and a new translation of Newton's Principia together with a Guide to the Principia.

Richard Dalitz is an emeritus Royal Society research professor in the University of Oxford. He has published several articles on the history of modern particle physics; present research is in high-energy particle physics, in terms of quarks, leptons, bosons and gluons.

John Fauvel teaches history of mathematics at the Open University, UK, and is a former president of the British Society for the History of Mathematics. Among the books he has written for and co-edited are The History of Mathematics: A Reader, Let Newton Be!, Mobius and His Band, and Oxford Figures: 800 Years of the Mathematical Sciences.

A. Rupert Hall has taught the history of science at Cambridge and at several US universities. In the course of half a century's study of Newton's writings, he has been the senior editor of three volumes of Newton's correspondence and published numerous books and papers, including a recent biography of Newton.

Michael Nauenberg is a professor emeritus of physics at the University of California at Santa Cruz. He has written several articles on the works of Hooke, Newton and Huygens, and reviews of books on Newton's Principia. He recently collaborated with J. Bruce Brackenridge on an article on Curvature in Newton's Dynamics to appear in the Cambridge Companion for Newton (edited by I. B. Cohen and G. Smith). 
Alan E. Shapiro is professor of the history of science and technology at the University of Minnesota. He is the editor of The Optical Papers of Isaac Newton and the author of Fits Passions and Paroxysms: Physics, Method and Chemistry, and Newton's Theories of Colored Bodies and Fits of Easy Reflection.

George E. Smith is a philosopher of science at Tufts University and a practicing engineer. His interests range from evidence in advanced sciences, engineering and medicine, and on the transition from speculation about the microphysical realm to systematic theory development during the course of late 19th and early 20 th century physics and chemistry.

D. T. Whiteside is a professor at Cambridge University where he has been since 1956. He is the editor of eight volumes of The Mathematical Papers of Isaac Newton and of many seminal papers which have greatly elucidated Newton's work.

Curtis Wilson was a professor in the Department of History at the University of California, San Diego (1968-1973). He was the first recipient of the LeRoy E. Doggett Prize for writing in the history of astronomy, American Astronomical Society (1998). Among his publications are: William Heytesbury: Medieval Logic and the Rise of Mathematical Physics (Wisconsin, 1956), and chapters in Planetary Astronomy from the Renaissance to the Rise of Astrophysics (edited by Rene Taton and C. Wilson). 


\section{Preface}

The initial conception of a Symposium on the Foundations of Newtonian Scholarship presented in this book, which was held in the Wellcome Hall of the Royal Society on 20 March 1997, stemmed from the realization that those interested in the life and work of Isaac Newton are living in a transition period. The eminent Newtonian scholars who have made accessible to us in a most remarkable way the vast mass of Newton's mathematical and scientific papers and correspondence, are still with us, mostly active and available for consultation, although in retirement or about to become so. Much new information about Newton's works has become readily available only in the last few decades and this has already led to significant recent developments in our understanding of Newton's Principia and of its origins and its proper interpretation on questions which had been obscure for several centuries. One editor (MN) and Professor Bruce Brackenridge, a member of the symposium organizing committee, have been fully aware of this situation for some time and have benefited from it, as this book attests. It was their desire to make this situation evident to scientists and mathematicians as well as to historians of science, young or established, which has led to this symposium. We hope that knowledge of these newly available sources may attract some of them to this research and that their work may lead to a deeper understanding of Newton's mathematical and scientific work and those of his contemporaries. This was a fundamental purpose of our symposium and its timing was motivated by the need for establishing contacts between new researchers thus attracted into this field and the eminent scholars who in the past have gained such a great familiarity with the development of Newton's scientific and mathematical style and abilities, and the lines of thought used by mathematicians in the late seventeenth century. This volume containing the proceedings of the symposium is also a tribute to their enormous accomplishments.

In 1985, the organizers of the Newton Tercentenary Conference, held at Cambridge University on 29 June-4 July 1987, proposed that Professor $\mathrm{S}$. Chandrasekhar, the great astrophysicist, should give an opening address 
with the title "The Principia Today". Chandrasekhar agreed to do so, if this new endeavor turned out to be possible for him. At this conference, Chandrasekhar's talk on the Principia was quite brief, being only a preliminary report. He said that he had decided to select a number of the propositions from the Principia, to construct proofs of them using the modern methods he was a master of, and then to compare his proofs with those given by Newton. He reported only that he had been left, again and again, in "sheer wonder at the elegance, the careful arrangement, the imperial style, the incredible originality and above all the astonishing lightness of Newton's proofs." These proofs took for granted the knowledge and experience of a body of geometrical and other mathematical relationships, which Newton could draw upon when needed, but which Chandrasekhar, as well as most modern readers of the Principia, did not readily have at hand as part of his intuition. Newton's proofs were economical and highly original, devised by Newton for his immediate purpose. Chandrasekhar found Newton's treatments most admirable, and it was not long before he felt it urgent to make his conclusions widely known and to have other physicists and mathematicians join him in his admiration of Newton. Since Chandrasekhar had been a colleague of the second editor (RHD) at the University of Chicago, it was natural for RHD to ask him to visit Oxford University and give a series of lectures about Newton and his Principia. He gave 10 lectures (all of which were well-attended by Oxford standards) in the Trinity term of 1991; it was an occasion not to be missed! At the end of his visit, the Oxford University Press sought to print his lectures in book form, which he agreed to do, after he had expanded his lectures somewhat and had had further experience with the Principia. His book was published in 1995 under the title "NEWTON'S PRINCIPIA for the Common Reader."

This book aroused much fresh interest about Newton, partly because Chandrasekhar laid out his treatments of the mathematical problems using modern methods well-known today, before comparing them with those of Newton. The Principia had always been considered a difficult book to read, suitable only for specialists and inaccessible even to other mathematicians and physicists, whereas Chandrasekhar's recasting of the propositions, lemmas and corollaries in modern terms made them readily intelligible and more readable. It has become known that, unfortunately, there are some serious errors in Chandrasekhar's book and that it is sometimes misleading, for he was not well-versed with the practice of mathematics in Newton's time, nor with the works of others beyond Newton at that time. Also, as he explicitly stated, he had made no use of the Foundation Works (see below), on which the papers 
of this symposium mostly depend. It has therefore been a controversial book, but a book which all those seriously interested in Newton and his Principia must read. Its great merit is that it has aroused much interest in this subject. Indeed, it has become a "best-seller," by the standards of academic books.

It is the custom for the Royal Society to require that a conference funded by its History of Science sub-committee should have at least one of its Fellows on its organizing committee. Given what has been recounted in the last paragraph above, it seemed natural that the second editor (RHD) should be the representative of the Royal Society for this symposium.

It is appropriate to add a few remarks concerning the publication of the Foundation Works:

\section{The correspondence of Isaac Newton}

This project was approved by the Council of the Royal Society in 1936, an editor was appointed in 1939, and work began in July of that year. But little progress was possible during World War II, and the pre-war editor died in 1946. A fresh start was made in 1947 when a Newton Letters Committee was set up to oversee the work; its chairman was Professor E.N. Andrade F.R.S., until his death on 6 June 1971. The project was given regular funding, from a grant obtained by the Royal Society for this purpose.

The editor for the first three volumes was Professor Herbert W. Turnbull, F.R.S., who died on 4 May 1961, just before Vol. 3 came out from the press. His assistant, Dr. Joseph F. Scott, edited Vol. 4 and continued as editor for Vol. 5 until his death in August 1971. Professor A. Rupert Hall and Dr. Laura Tilling were then appointed joint editors for the last three volumes, 5 to 7 . The overall task was very considerable indeed. It had been decided to publish all of the letters which could be found, whether to or from Newton. According to Turnbull, Newton did not normally keep drafts of the letters he wrote during his Cambridge period, and it was necessary to search for his letters among those the recipients may have retained. According to Hall and Tilling, Newton often made many drafts during his London period; when the final letter was available, their comparison with these drafts showed that the last draft and the final letter were essentially the same. It was also decided to include letters between two other persons, where the contents (in part, if not in full) had bearing on Newton's work. Letters in Latin were to be published as such, with an English translation following each, together with endnotes concerning them. Further, notes jotted down by the sender and/or the recipient in preparing a 
letter and/or analyzing a letter received, were to be added, as appropriate. It was also necessary for the editors to understand correctly the matters referred to in all these letters, taking into acccount other developments in mathematics and astronomy going on at the same time; the editors of the last three volumes give thanks to Professor D.T. Whiteside for his advice about these matters, and for his good sense and scholarship in this respect. To emphasize the magnitude of the task, we give a short table to provide a quantitative summary of the outcome, over a period of almost 35 years of work.

Table 1 The correspondence of Isaac Newton.

\begin{tabular}{|c|c|c|c|c|c|c|c|}
\hline Volume & 1 & 2 & 3 & 4 & 5 & 6 & 7 \\
\hline Years & $1661-1675$ & $1676-1687$ & $1688-1694$ & $1694-1709$ & $1709-1713$ & $1713-1718$ & $1718-1727$ \\
\hline Publication & 1959 & 1960 & 1961 & 1967 & 1975 & 1976 & 1981 \\
\hline pp.* & $(38,468)$ & $(13,552)$ & $(18,445)$ & $(32,577)$ & $(51,439)$ & $(38,499)$ & $(45,522)$ \\
\hline Editors & \multicolumn{3}{|c|}{ H.W. Turnbull } & J.F. Scott & \multicolumn{3}{|c|}{ A.R. Hall \& L. Tilling } \\
\hline
\end{tabular}

*In (a, b), a gives the prefatory pages, b gives the pages of text.

\section{The mathematical papers of Isaac Newton}

The publication of these papers followed a different pattern, rather unplanned. Remarkably, Professor D.T. Whiteside became the sole editor of the complete series of eight volumes from about 1960 to 1981, when the last volume came off the press. He recorded the supportive assistance he received from Dr. Michael Hoskin and Mr. Adolf Prag, the former mostly in the early years and the latter mostly in the later years. The funding of this project was irregular. Whiteside first came into contact with Sir Harold Hartley in 1959, in assisting him to put together and publish a book entitled "The Origins and Founders of the Royal Society" (Cambridge University Press, 1960) to mark the tercentenary of the foundation of the Royal Society in 1660 . Hartley had always had a great interest in the history of science. When he saw what research Whiteside was doing for his Ph.D. thesis, he made it his business to keep Whiteside funded in the crucial period after completion of his dissertation - his research studentship ended in the early summer of 1959 , and approval of his thesis for the Ph.D. degree by the Board of Research Studies of Cambridge University took place at their meeting in December 1960 - encouraging him and making it financially possible for him to continue his research, far beyond his dissertation, until it became the critical editing and the publishing of all of the mathematical pa- 
pers of Isaac Newton. In the earlier part of his life, say up to 1960, Hartley had an unusually broad range of official and semi-official contacts and connections in Britain. With his unrivalled knowledge of the ropes, he was able to approach fruitfully all possible sources for the support of Whiteside and his project. By the time Hartley died (in 1971), Whiteside had become established and his funding had become regularly available, although from a number of independent sources and at a modest level. It is not surprising that, in our symposium, Whiteside's thoughts went back to those crucial early years, when he had been encouraged by, and supported through, his patron Hartley.

Whiteside's task was immense, for the mathematical papers were incomplete and unordered. He had to comprehend, date and correlate the various drafts and fragments of Newton's work as he moved towards the Principia. His ability to carry so many threads in his mind and to connect them correctly when needed is clearly most unusual. There are very few who could have done this work in such a reliable and thorough way. There are still obscurities about the degree of dependence between different papers to be understood and doubtless many pages were missing; what is remarkable is how much of Newton's calculations has survived and how Whiteside has been able to pull it all together and relate it with work going on by other mathematicians and scientists in Newton's time.

Most of Newton's papers are in Latin, and this original version is printed on the left pages of Whiteside's editions, together with an English translation on the right pages, although sometimes this translation is missing. The footnotes are very considerable, scholarly, and informative. Marvellously helpful is the Analytic Table of Contents at the front of each volume, typically being about 35 pages for about 500 pages of text. They give a precis from page to page through the text, giving enough information for the reader to readily find what he needs.

To illustrate the magnitude of Whiteside's achievement, the following summary table gives a quantitative measure of the final result, over a period of about 20 years.

Table 2 The Mathematical Papers of Isaac Newton (edited by D.T. Whiteside).

\begin{tabular}{|l|cccccccc|}
\hline Volume & 1 & 2 & 3 & 4 & 5 & 6 & 7 & 8 \\
\hline Years & $1664-1666$ & $1667-1670$ & $1670-1673$ & $1674-1684$ & $1683-1684$ & $1684-1691$ & $1691-1695$ & $1697-1722$ \\
Publication & 1967 & 1968 & 1969 & 1971 & 1972 & 1974 & 1976 & 1981 \\
pp.* & $(46,590)$ & $(22,520)$ & $(38,576)$ & $(32,678)$ & $(22,627)$ & $(34,614)$ & $(47,706)$ & $(55,704)$ \\
\hline
\end{tabular}

*In $(\mathbf{a}, \mathbf{b})$, a gives the prefatory pages, $b$ gives the pages of text. 


\section{Other Foundation Works In This Century}

I. Bernard Cohen, Introduction to Newton's Principia (Cambridge, Cambridge University Press, 1971).

Isaac Newton's Philosophiae Naturalis Principia Mathematica (1726 edition, with variant readings (eds.) I.B. Cohen \& A. Koyre) two volumes (Cambridge, Cambridge University Press, 1972).

These three volumes go together. The latter two give a clear printing of the Latin text of the 1726 Principia, with brief footnotes (typically ten lines) in English. Pages 1 to 547 are in Vol. 1 and 548 to 771 in Vol. 2, together with ten Appendices, running from p. 775 to p. 916 in the latter. The variant readings display the differences in text between the 1726 edition of the Principia and the 1687 and 1713 editions, all of which which were directly supervised by Newton. These readings are the subject of the footnotes in Vols. 1 and 2 which contain also corrections and additions made by Newton into his personal copies of the first and second editions. A Guide is given on pp. ix to $\mathrm{xl}$ of Vol. 1. The MS for the two (1972) volumes was completed long before Koyre's death in 1964. The 1971 volume is exhaustive in its detailed documentation of the early manuscripts which led to the Principia, including discussion of those manuscripts with proposed revisions which Newton did not implement.

Isaac Newton, Mathematical Principles of Natural Philosophy, translated from Latin to English by I. Bernard Cohen and Anne Whitman with the assistance of Julia Budenz, with a Guide to the Principia by I. Bernard Cohen (Berkeley, Los Angeles, London, University of California Press, 1999).

The Optical Papers of Isaac Newton, Vol. 1 (The Optical Lectures, 16701672), edited by Alan E. Shapiro (Cambridge University Press, 1984); Vol. 2, in preparation. The first volume contains two versions of The Optical Lectures which Newton delivered at the University of Cambridge. One of these versions is the Optica, which Newton deposited in the University Library for public use, while the other version, the Lectiones Opticae, was kept by him and eventually became part of the Portsmouth collection. Both versions are reproduced in its original Latin text on the left page together with an English translation on the right page with extensive explanatory footnotes.

Isaac Newton, Opticks Or A Treatise of the Reflections, Refractions, Inflections $\&$ Colours of Light, based on the fourth edition London, 1704 (Dover publications, 1952). With a Foreword by Albert Einstein, an Introduction by Sir Edmund Whittaker, a Preface by I. Bernard Cohen and an Analytical Table of Contents prepared by Duane H.D. Roller. 
John W. Herivel, The Background to Newton's Principia: A Study of Newton's Dynamical Researches in the years 1664-1684 (Oxford, Clarendon Press, 1965).

A. Rupert Hall and Marie Boas Hall, Unpublished Scientific Papers of Isaac Newton (Cambridge University Press, 1962).

The original program for the symposium included a concluding talk to be given in the evening by Richard Samuel Westfall, the author of an excellent biography of Newton, "Never at Rest." Unexpectedly, he died on 21 August 1996, a serious loss to us all, and unfortunate for the symposium. Professor Curtis Wilson agreed to give the concluding talk, but was prevented from attending the symposium by an illness at the last minute. Fortunately, he provided us with the manuscript for his talk which was delivered by D.T. Whiteside at the appointed time, with Marie Boas Hall as Chair. Both Rupert Hall and Whiteside were present, each speaking at, and contributing to, the symposium and its discussions. The other speakers gave talks illuminating various aspects of Newton's work, in the light of the Foundation Works.

The symposium was supported by grants from the Royal Society, through its History of Science sub-committee, from the National Science Foundation (U.S.A.) and from the History of Science Society (U.S.A.), and we thank them all for making this Symposium on the Foundations of Newtonian Scholarship possible. We would like to thank also Susan Johnson Cohen for taking most of the photographs of the speakers, which have been placed for each speaker on the page opposite the beginning of his lecture, and Professor David Fowler for the excellent group photograph which is placed on the page opposite this Preface. Above all, we are immensely grateful to the Royal Society for their permission to reproduce their fine portrait of Isaac Newton made by J. Vanderbank in 1726. We are very glad that it was possible for us to hold the symposium in the present building of the Royal Society, because of Newton's early and most important association with the Society, being its President from 1703 when Robert Hooke died, until the the end of his life in 1727. Today this association is made apparent by the five portraits, one of which is on the cover of this book, and one bust of Newton to be found in the Royal Society building.

Michael Nauenberg,

Physics Department, University of California, Santa Cruz CA 95064 U.S.A
Richard H. Dalitz, Theoretical Physics Department, Oxford University, 1 Keble Rd, Oxford OX1 3NP, U.K. 
This page is intentionally left blank 


\section{Contents}

Contributors' Biographies vii

Preface $\quad$ ix

Introduction 1

Newton's Scholarship in Historical Perspective 11

I. Bernard Cohen

Newton's Experimental Investigation of Diffraction for the

Opticks: A Preliminary Study

Alan E. Shapiro

Comparison of Newton's Diffraction Measurements With the

Theory of Fresnel

Michael Nauenberg

Newton's Dynamics: The Diagram as a Diagnostic Device

J. Bruce Brackenridge

Fluid Resistance: Why Did Newton Change His Mind?

George E. Smith

Addendum to G. Smith's "Fluid Resistance: Why did Newton

Change his Mind?"

Michael Nauenberg

Newton's Mathematical Language

John Fauvel

Newton's Expansion for the Square Root of an Algebraic Equation by an Equivalent Arithmetic Method

Michael Nauenberg 
xviii Contents

Newton's Portsmouth Perturbation Method and its Application to Lunar Motion

Michael Nauenberg

Review and Reminiscences

A. Rupert Hall

How Does One Come to Edit Newton's Mathematics?

Derek Thomas Whiteside

From Kepler to Newton: Telling the Tale

Curtis Wilson 